INCOTW - Sassari, Italy (2017)

"International Congress on Cork Oak Trees and Woodlands"

Guest Editors: Piermaria Corona, Sandro Dettori

\title{
Feasibility study of near infrared spectroscopy to detect yellow stain on cork granulate
}

David Pérez-Terrazas ${ }^{(1)}$ José Ramón González-Adrados ${ }^{(2)}$, Mariola Sánchez-González ${ }^{(1)}$

The aim of this study was to evaluate the viability of near infrared spectroscopy (NIRS) to detect the anomaly known as yellow stain on cork granulate. Detecting this anomaly is crucial to the cork granulate stopper industry, since it is associated with the presence of 2,4,6-Trichloroanisole (TCA), this compound having been identified as the main agent responsible for cork offflavours. Samples for the NIRS spectra were prepared by mixing in different proportions cork granulate with high visual quality and cork granulate with yellow stain, obtaining 120 samples with 8 different percentages of yellow stain $(0,5,10,15,25,35,50$ and $100 \%)$. Two spectra per sample were collected using a Bruker MPA spectrophotometer and the partial least squares (PLS) method was used to obtain numerous equations. The best equation was obtained by utilizing the standard normal variate (SNV) spectral preprocessing, making use of only one specific part of the near infrared spectral range: 9400 $4250 \mathrm{~cm}^{-1}$. This equation shows a coefficient of determination $\left(R^{2}\right)$ of $99.42 \%$, a root mean square error of cross validation (RMSECV) of $2.34 \%$, and a residual prediction deviation (RPD) of 13.10. The critical level and the limit of detection are $3.8 \%$ and $7.6 \%$, respectively. The calculated receiver operating characteristic (ROC) curves show great discrimination capacity and the area under the ROC curve (AUC) is higher than 0.93 in any case. This study demonstrates that NIRS provides a viable technique for detecting yellow stain in cork granulate.

Keywords: Cork, Granulate, Yellow Stain, 2,4,6-Trichloroanisole, TCA, Near Infrared Spectroscopy, NIRS

corresponds to Portugal and $30.5 \%$ to Spain (APCOR 2016). Cork has numerous applications though the most important of these in economic terms is the manufacture of different types of cork stoppers to be used in the bottling of wines (Sánchez-González et al. 2016). It is the suitability of the raw cork material for this production that establishes its commercial value (Pereira 2007). Agglomerated, micro-agglomerated and technical stoppers are made from cork granulate which is obtained by grinding the cork that is not suitable for the production of natural cork stoppers and disks, as well

(1) INIA-CIFOR, Ctra. de La Coruña km 7.5, E-28040 Madrid (Spain); (2) MONTES (School of Forest Engineering and Natural Environment), Universidad Politécnica de Madrid, C/ José Antonio Novais s/n, E-28040 Madrid (Spain)

@ David Pérez-Terrazas (david.perez@inia.es)

Received: Jul 25, 2017 - Accepted: Dec 12, 2017

Citation: Pérez-Terrazas D, González-Adrados JR, Sánchez-González M (2018). Feasibility study of near infrared spectroscopy to detect yellow stain on cork granulate. iForest 11: 111117. - doi: 10.3832/ifor2563-010 [online 2018-01-31]

Communicated by: Piermaria Corona

as from the waste generated during cork manufacturing (Sánchez-González et al. 2015). Cork granulate is defined as cork fragments between 0.2 and $8.0 \mathrm{~mm}$ in size (UNE-ISO-633 2010) and represents an important part of the cork industry, accounting for $75 \%$ of total cork (Gil 2009).

One of the main problems for the cork industry is the presence of 2,4,6-Trichloroanisole (TCA - Barreto et al. 2011). This compound has been identified as the main agent responsible for cork off-flavours ( $\mathrm{Ca}$ pone et al. 2002, Soleas et al. 2002) and is formed through fungal degradation of the chlorophenols present in the cork. Various studies have attributed this phenomenon to different species of fungi such as Penicillium and Aspergillus (Calvo et al. 1995) or Armillaria (Rocha et al. 1996). TCA has mould-like taste that will be present in the wine (Rocha et al. 1998) and it also has a very low detection threshold, $1.4-4 \mathrm{ng} \mathrm{l}^{-1}$ (Garcia et al. 2015). Attenuated total reflection infrared spectroscopy (ATR-IR) proved that the presence of TCA modifies the cork spectra (Garcia et al. 2015). In this regard, two new bands appeared at 1417 and 1314 $\mathrm{cm}^{-1}$ and the relative intensities of the bands increased at 1039 and $813 \mathrm{~cm}^{-1}$ (Garcia et al. 2015). At present, TCA control is 
only being developed for cork stoppers, using chromatographic (ISO-20752 2014) or sensory techniques (ISO-22308 2005) and research is ongoing in this area (Slabizki et al. 2015, Slabizki et al. 2016). However, these techniques cannot be applied to raw material (planks or granulate) for 2 reasons, namely, the high cost and high variability of the material.

The cork defect known as "yellow stain" was identified as far back as 1900 (Bordas 1904). Studies performed using scanning electron microscopy (SEM) carried out on healthy cork and cork with yellow stain showed that the cellular structures of the infected and the healthy tissues were different, and that the tissues attacked were composed of deformed, wrinkly cells with cell wall separation at the middle lamella level (Rocha et al. 1996). These changes were related to the degradation of lignin and pectin, as evidenced by the deposition of calcium in the intercellular space of the cells attacked (Rocha et al. 1996). Comparative chemical studies showed that the cork attacked by yellow stain suffered a degradation of tannins with consequent discoloration (García-Vallejo et al. 2001) along with a biosynthesis of TCA (Moio et al. 1998).

Hence, the industry would greatly benefit from the development of a method to control the presence of yellow stain in cork granulate. If cork granulate affected by yellow stain and therefore by TCA is not removed from the production line, the granulate cork stoppers produced using this defective material will have a mould-like taste and therefore will not be suitable for wine bottle closure. Near infrared spectroscopy (NIRS) is potentially suitable for detecting yellow stain in cork granulate, since it is widely used in quality control of granulated products in the food and agriculture indus-

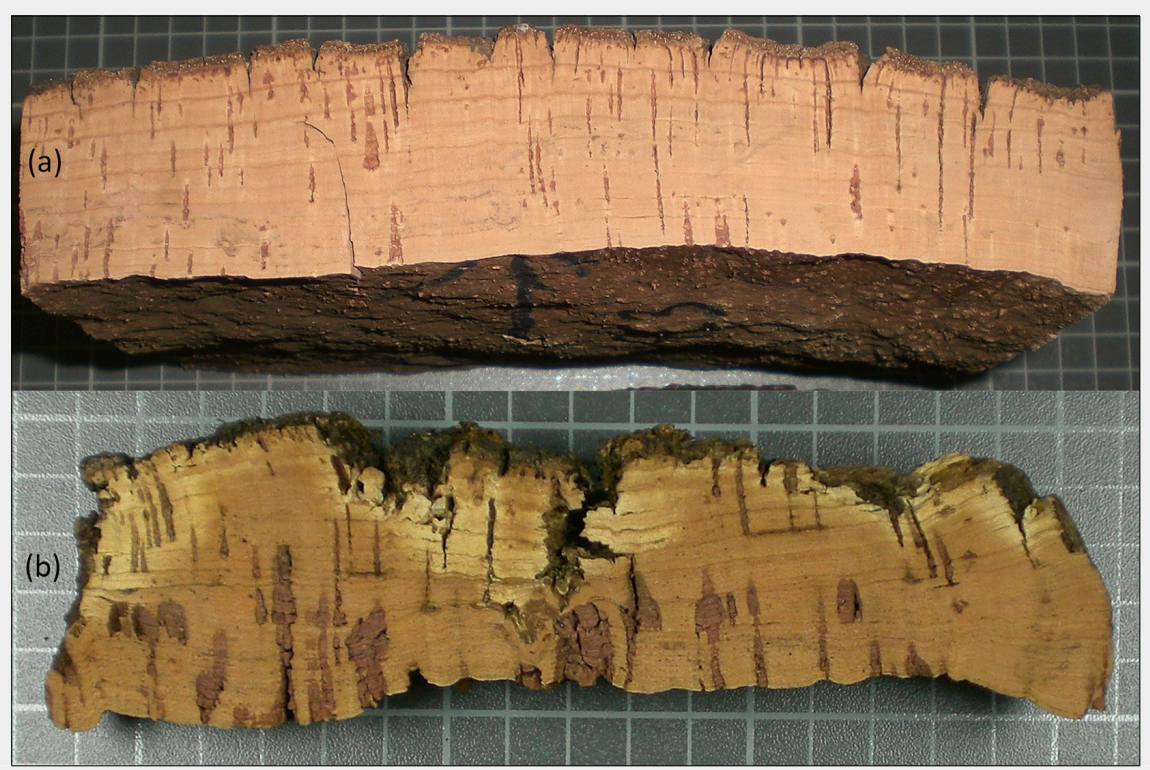

Fig. 1 - (a) Piece of cork classified as highest visual quality (HQ); (b) piece of cork with yellow stain clearly present (YS). try (Magwaza et al. 2012, Pojić \& Mastilović 2013). In addition, NIRS has certain advantages over other analytical methods, such as rapid and non-destructive analysis, low analyzing costs and easy sample preparation. Furthermore, it can also provide information on different variables simultaneously.

The first application of NIRS technology to cork was a viability study to assess its potential for characterizing cork planks according to visual quality, porosity and moisture content, and for predicting the geographical origin of cork planks (Prades et al. 2010). The potential of this technology as a method for predicting the geographical origin of cork planks and stoppers has been demonstrated (Prades et al. 2012). It allows continuous quality control of moisture content in cork stoppers while simultaneously obtaining other parameters such as chemical components (waxes and total polyphenols) along with physical and mechanical parameters (density, extraction force and compression force) (Prades et al. 2014). It is useful for determining the porosity of cork planks before and after boiling (Sánchez-González et al. 2016). The last application of this technology is the development of NIRS models to predict the technological parameters (caliper, earthy cork, blown cork, belly and stained cork) on cork planks (Prades et al. 2017).

The aim of this study is to develop calibration equations to predict the percentages of yellow stain in samples of cork granulate and thereby evaluate the viability of NIRS as a method to detect cork with yellow stain on the production line. Numerous spectra preprocessing and spectral ranges were studied to determine the most suitable. Lastly, critical level, limit of detection and receiver operating characteristic (ROC) curves of the equations were also studied.

\section{Material and methods}

\section{Samples and sample preparation}

Cork pieces used in this study were collected in a sampling carried out in Catalonia (Spain) in 1991 and form part of the INIACIFOR cork laboratory collection. Two groups were selected: pieces classified as being of the highest visual quality ( $\mathrm{HQ}$ Fig. 1a), completely free of defects, and pieces where yellow stain was clearly present (YS - Fig. 1b).

Five strips of $0.5 \mathrm{~cm}$ thickness were cut from the cross section on all the pieces from both groups and the corkback (phloemic tissue remaining on the outer side of the cork) was removed. In the case of YS pieces, areas presenting yellow stain were separated, so that areas of "pure cork" and "stained cork" were separately ground and sieved $(0.5-1 \mathrm{~mm})$ in order to obtain cork granulate of two types: one comprising $100 \%$ highest visual quality cork with no defects , and the other, $100 \%$ yellow stained cork. Both types of cork granulate were dried at $103^{\circ} \mathrm{C}$ to constant weight and later conditioned in a container at constant temperature. When the samples were scanned, average moisture content was $4.5 \%$.

Samples for the NIRS spectra were prepared by mixing both types of cork granulate in different proportions, obtaining samples with different percentages of yellow stain (YSP). These percentages were established such that the range was as large as possible while at the same time having a greater incidence of lower values: $0,5,10,15,25,35,50$ and $100 \%$. The amount of granulate per sample was fixed at 2.5 grams and the number of samples per percentage of yellow stain was 15 , making a total of 120 samples.

\section{Instrumentation and collection of} spectra

Samples were scanned using a Bruker MPA $^{\oplus}$ spectrophotometer (Bruker Analytical Systems, Billerica, MS, USA) that measures diffuse reflectance. Spectra were collected every $16 \mathrm{~cm}^{-1}$ from $12,500 \mathrm{~cm}^{-1}$ to $3,600 \mathrm{~cm}^{-1}$ using OPUS software.

Each sample was weighed prior to analysis on a precision scale of $0.1 \mathrm{mg}$. Two spectra per sample were obtained making a total of 240 spectra. These spectra were stored as $\log (1 / R)$ and were used to determine the percentage of yellow stain. The integrating sphere with a rotating system was used as a measuring channel and the area of spectrum was a circular crown of $35.34 \mathrm{~cm}^{2}$.

\section{Quantitative analysis}

Spectra were collected and quantitative analysis was performed using OPUS software ver. 7.5. Prior to the calibration, the two spectra taken for each of the samples were averaged, performing calibration with the 120 average spectra. The partial least squares (PLS) method was used to obtain the equations and the maximum 
number of PLS vector was set at 10 . Numerous equations were obtained using an algorithm from the OPUS software, which allows around 200 combinations of different preprocessings to be performed along with various preset spectral ranges. The distance of each of the spectra from the center of the space defined by the entire population, known as Mahalanobis distance, was calculated. If the Mahalanobis distance is greater than 3 for a given sample, the software classifies it as a spectral outlier. OPUS software also calculates the chemical anomaly, defined as samples with significant differences between their actual and predicted values.

Equations were validated by means of cross-validation in order to include all of the spectral variability of the data set. The best equations were selected taking into account the lowest value of the root mean standard error of cross validation (RMSECV) and the highest value of the coefficient of determination $\left(R^{2}\right)$. Another method of assessment used to evaluate the calibration was residual prediction deviation (RPD). It is calculated as the ratio of two standard deviations; the standard deviations of the reference data as measured using the conventional method and the standard error of cross-validation (Williams \& Sobering 1993). Calculation of RPD allows to compare calibrations that have differing data ranges or have different treatments and properties. The higher the RPD, the more precise the data described by the calibration. The last statistic used to evaluate the calibration was systematic error or BIAS, which allows to determine whether the calibration equation overestimates or underestimates. The three best equations were selected.

In order to evaluate the discrimination capacity of the different equations, that is, the ability to differentiate between presence or absence of yellow stain rather than to determine the percentage present, we used detection probability (also termed true positive or sensitivity) and false positive probability (1-specificity) by means of the critical level $\left(L_{c}\right)$, the limit of detection $\left(L_{\mathrm{D}}\right)$ and the receiver operating characteristics (ROC) curves. These concepts are related through the distribution of outcomes, more specifically, the mean and the standard deviation of those distributions (Knoll 2010). When performing a discriminate test in a certain population in which one part of this population has a disease (or anomaly) and the other part does not, we would not expect to observe a perfect separation between the two groups but rather, the distribution of the test results will overlap (Fig. 2a). As regards the population with the disease, two cases are possible: true positive or sensitivity, when cases are correctly classified as positive and false negative or error type II, when cases are wrongly classified as negative (values higher than $L_{\mathrm{c}}$ ). Similarly, two cases are also possible for the population with-

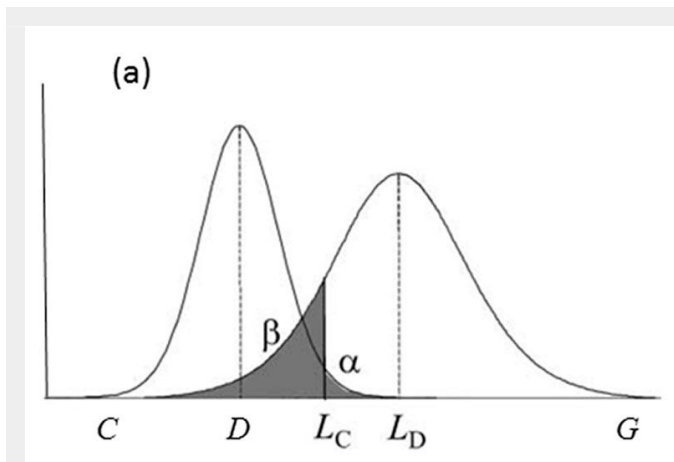

(b)

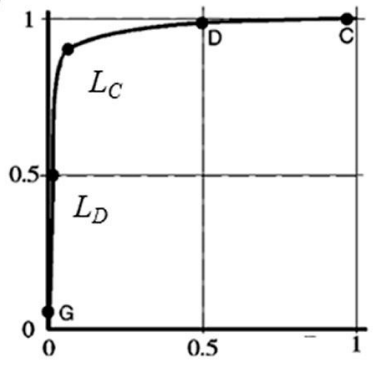

Fig. 2 - (a) Example plots of the probability distributions of total samples with disease (right) and number of samples without disease (left). ( $\left.L_{\mathrm{C}}\right)$ : critical level; $\left(L_{\mathrm{D}}\right)$ : limit of detection; $(\alpha)$ : probability of committing a type I or false positive error (analysis of a white gives a positive yellow stain); $(\beta)$ : probability of making a type II or false negative error (analysis of a sample with yellow stain gives a negative yellow stain). Modified from Boqué (2004). (b) The corresponding receiver operating characteristic (ROC) curves for the distributions shown in (a). Modified from Knoll (2010).

out disease: true negative or specificity, when cases are correctly classified as negative and false positive or error type I when cases are wrongly classified as positive (values lower than $L_{c}$ ).

In our case, critical level $\left(L_{c}-\right.$ eqn. 1$)$ and limit of detection ( $L_{D}-$ eqn. 2) were calculated as follows (Boqué 2004):

$$
\begin{aligned}
& L_{C}=t_{1-\alpha, v} \cdot s_{0} \\
& L_{D}=2 \cdot t_{1-\alpha, v} \cdot s_{0}=2 \cdot L_{C}
\end{aligned}
$$

where $t_{1-a, v}$ is the value of a $t$-Student distribution for a level of significance $\alpha$ and $v$ degrees of freedom, and $s_{0}$ is the estimate of the standard deviation when yellow stain is not present in the sample. Critical level and limit of detection were calculated for the three best equations.

ROC curves represent sensivity vs. 1- specificity (Fig. 2b), according to a particular critical level or decision threshold. The area under this curve (AUC) measures the accuracy of the detection system. The closer the curve to the upper left corner of the graph, the greater the accuracy of the calibration (Zweig \& Campbell 1993). The AUC statistic is a threshold-independent measure of the accuracy of the discriminant equation, in which values equal to or less than 0.5 indicate no discrimination, values between 0.7-0.8 indicate an acceptable discriminating capacity, and values between 0.8-0.9 or higher indicate excellent discriminations (Hosmer \& Lemeshow 2000). A total of 7 ROC curves were calculated for the best equation, varying the size of the subpopulation that is compared with the subpopulation of 15 white samples. In the first calculation, all samples are used, while in the last one only those with $5 \%$ of yellow stain are entered.

\section{Results and discussion}

\section{Spectra}

Fig. 3 shows the mean spectra obtained for each of the different percentages of yellow stain in the zone with the absorption peaks. As far as we know, the spectra obtained in this study are the first spectra of cork granulate with different percentages of yellow stain in the near infrared zone. The spectra show the characteristic bands reported in previous studies on cork

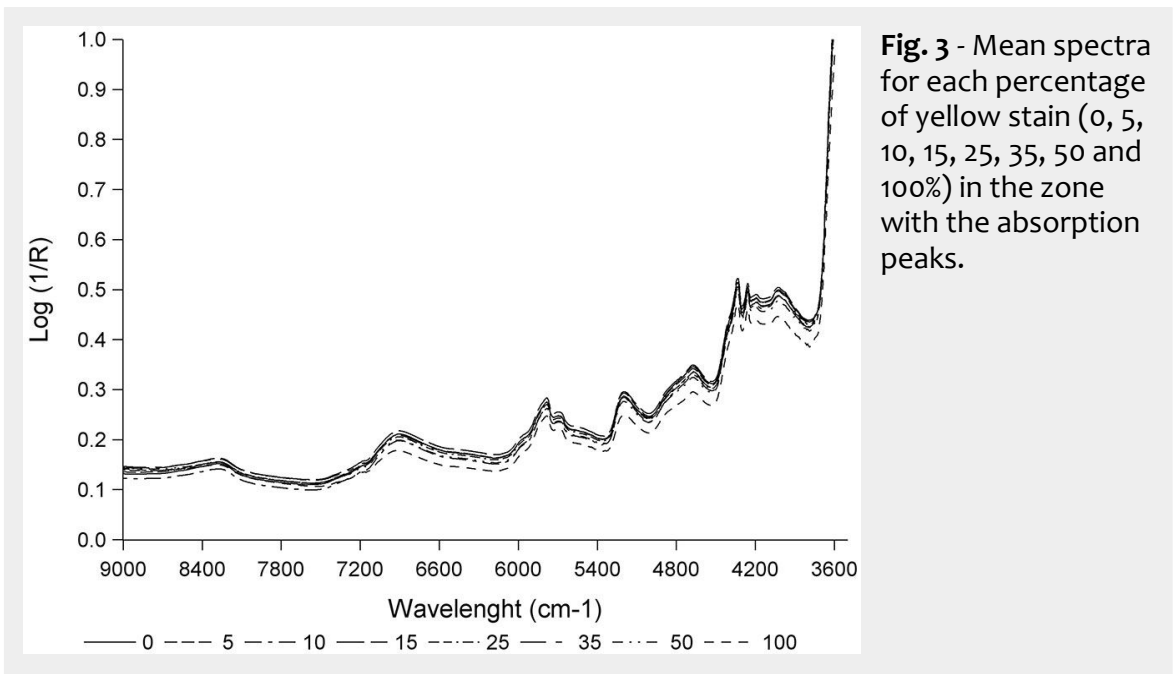


Tab. 1 - Statistics obtained for the three best NIRS calibration equations. Number of PLS vectors (Rank), root mean square error of cross validation (RMSECV), coefficient of determination $\left(\mathrm{R}^{2}\right)$, residual prediction deviation (RPD) and systematic error (BIAS).

\begin{tabular}{lcccrc}
\hline Equation & Rank & RMSECV (\%) & $\mathbf{R}^{2}$ (\%) & RPD & BIAS \\
\hline Equation 1 & 8 & 3.28 & 98.86 & 9.35 & 0.0356 \\
Equation 2 & 6 & 3.16 & 98.93 & 9.68 & 0.0377 \\
Equation 3 & 8 & 2.34 & 99.42 & 13.10 & -0.0429 \\
\hline
\end{tabular}

Fig. 4 - Root mean standard error of cross validation

(RMSECV) versus number of PLS vectors (Rank) for Equation 3.

गे

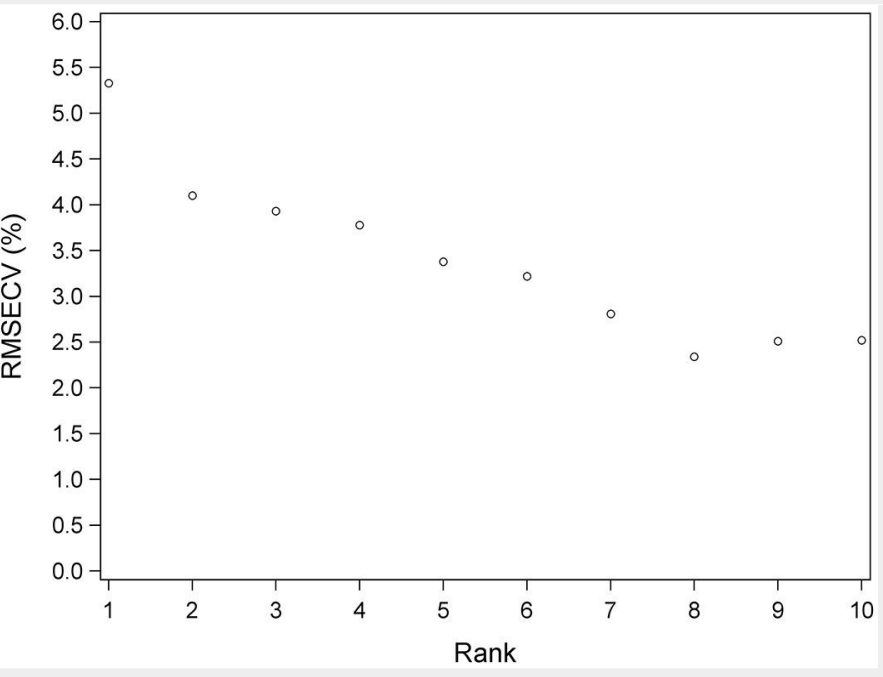

Fig. 5 - Predicted values versus actual values for Equation 3. Solid line represents the regression line. Dark shaded region shows the $95 \%$ confidence interval and dashed lines are upper and lower $95 \%$ prediction intervals of the regression.

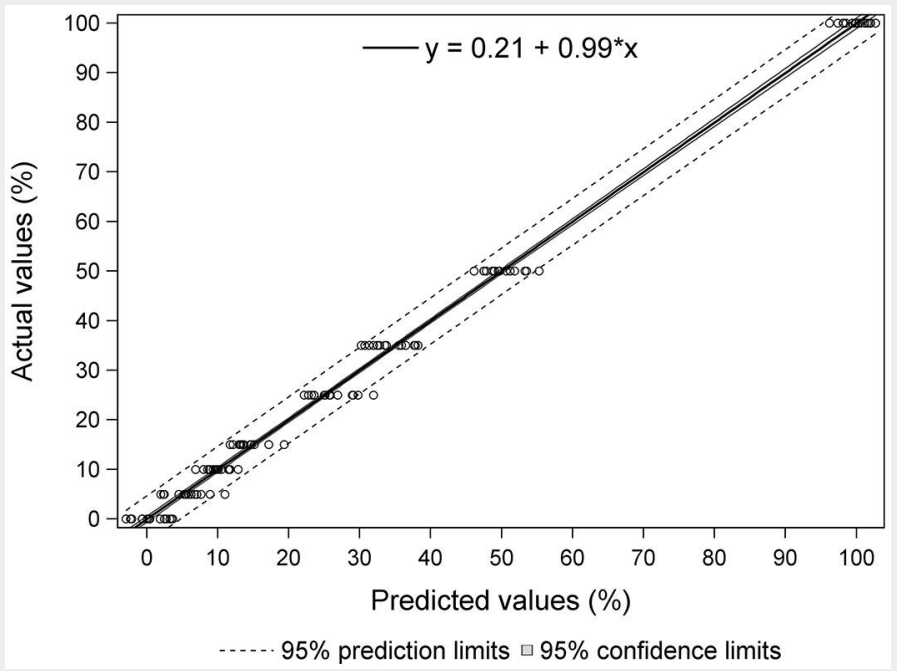

Fig. 6 - Actual values vs. difference values for Equation 3. Difference values is the difference between actual values and predicted values. Solid line represents the reference line $y=0$.

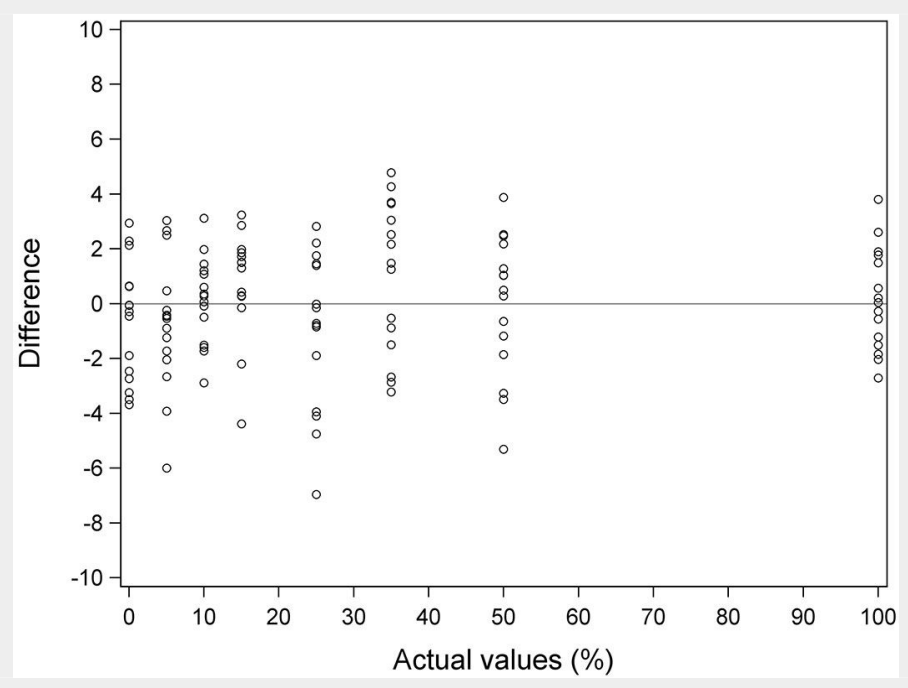

plank, stoppers or granulate, corresponding to $-\mathrm{CH},-\mathrm{OH}$ and $\mathrm{C}=\mathrm{O}$ groups. Specifically, bands of 8230 and $5714 \mathrm{~cm}^{-1}$ correspond to the second and the first overtone of $-\mathrm{CH}$ groups. Bands of 6890 and $5180 \mathrm{~cm}^{-1}$ belong to the first overtone and combination bands of the -OH group. The band of $4650 \mathrm{~cm}^{-1}$ corresponds to the combination bands of the $-\mathrm{CH}$ and $\mathrm{C}=0$ groups. Lastly, 4350 and $4240 \mathrm{~cm}^{-1}$ bands are associated with the combination bands of the $-\mathrm{CH}$ groups (Prades et al. 2010, 2012, 2014, 2017, Sánchez-González et al. 2016).

All spectra show the same absorption bands though the intensity differs for each of them. The spectrum of $100 \%$ yellow stain shows the highest absorption, spectra of 0 , $5,10,15,25$ and $35 \%$ show the lowest absorption and the spectrum of $50 \%$ shows an intermediate absorption. Therefore, the absorption decreases as the percentage of yellow stain declines.

\section{Calibration equations}

Tab. 1 shows the statistics for the three best NIRS calibration equations. Equation 1 was developed using the entire NIRS region, without any preprocessing of the spectra. Equation 2 was developed using standard normal variate (SNV) spectrum preprocessing and also used the whole NIRS region. The last equation (Equation 3) was developed using only part of the NIRS region, $9400-4250 \mathrm{~cm}^{-1}$, using SNV preprocessing of the spectra. This region of the near infrared coincides with the absorption peaks previously described. No spectral outliers appeared in any of the three equations, nor were there samples classified as chemical anomalies.

The number of PLS vectors or rank was 8 for Equations 1 and Equation 3 and was 6 for Equation 2. Fig. 4 shows the evolution of RMSECV as the ranking for Equation 3 increased. As can be seen, from rank 8 onwards, the RMSECV increases slightly.

The RMSECV obtained in the three equations was similar and ranges from $3.28 \%$ (Equation 1) to $2.34 \%$ (Equation 3), revealing that the equations developed predict the percentage of yellow stain with a high level of precision. The $\mathrm{R}^{2}$ was greater than 98\% for Equations 1 and Equation 2, and greater than $99 \%$ for Equation 3, so more than $98 \%$ and $99 \%$ respectively of the data variability is explained by the equations. The RPD values were above 8 (between 9.35-9.68) for Equations 1 and Equation 2, indicating that the equations are satisfactory for quality assurance (QA). In Equation 3, the RPD value was above 13 (13.1), indicating that the equation is like the reference (Williams \& Sobering 1996). The BIAS values were positive for Equations 1 and Equation 2, and negative for Equation 3. A negative BIAS indicates that the equation overestimates the percentage of yellow stain, which is preferable as it provides greater assurance when estimating an anomaly.

Fig. 5 shows the percentages of yellow 
stain predicted by the equation vs. the real values for each of the samples in the case of Equation 3. It also shows the prediction limit and the confidence limit to $95 \%$ and the regression line $(y=0.21+0.99 \cdot x)$. It can be observed that the estimated values display a compact distribution around the real value, evidencing the accuracy of the calibration. All samples were within the $95 \%$ prediction limits except for three, one of $5 \%$, another of $25 \%$ and another of $50 \%$ yellow stain. As regards the samples with $15 \%$ or less yellow stain (in industry, yellow stain is always found in low percentages, so this is the level of most interest), all samples were within the $95 \%$ prediction limits, except for the $5 \%$ yellow stain sample mentioned above.

Fig. 6 shows actual values vs. the difference between actual and predicted values for each of the samples in the case of Equation 3. For most of the samples the difference between the actual and the predicted value was less than $3.5 \%$ in absolute value. Only three samples presented a difference greater than $5 \%$ in absolute value $(-5.31 \%$ for the $50 \%$ yellow stain sample, $-6.00 \%$ for the $5 \%$ sample and $-6.96 \%$ for the $25 \%$ sample). These three samples correspond to those that are beyond the $95 \%$ prediction limits. It is important to note that the largest differences are associated with overestimates (preferable when estimating an anomaly). The biggest difference due to underestimation was 4.78 for a sample with $35 \%$ yellow stain. In the case of samples with $15 \%$ or less yellow stain, the biggest difference due to underestimation was $3.24 \%$ for a sample with $15 \%$ yellow stain.

\section{Discrimination capacity of the} calibration equations

To calculate the critical level and the limit

Tab. 2 - Critical level $\left(L_{C}\right)$ and limit of detection $\left(L_{\mathrm{D}}\right)$ for the three best NIRS calibration equations. $\left(s_{0}\right)$ : standard deviation of the predicted values for samples with $0 \%$ yellow stain for each of the equations.

\begin{tabular}{lccc}
\hline Equation & $\boldsymbol{s}_{0}$ & $\boldsymbol{L}_{\mathrm{c}}(\%)$ & $\boldsymbol{L}_{\mathrm{D}}(\%)$ \\
\hline Equation 1 & 4.2 & 7.4 & 14.8 \\
Equation 2 & 3.7 & 6.5 & 13.0 \\
Equation 3 & 2.2 & 3.8 & 7.6 \\
\hline
\end{tabular}

of detection it is necessary to estimate the standard deviation of the predicted values for the 15 samples with $0 \%$ yellow stain for each of the equations $\left(s_{0}\right)$. These were $4.2 \%, 3.7 \%$ and $2.2 \%$ respectively. Tab. 2 shows the results for the critical level $\left(L_{C}\right)$ and the limit of detection $\left(L_{\mathrm{D}}\right)$ for the three equations.

The best result for critical level and limit of detection was also obtained with Equation 3. The critical level was $3.8 \%$. Therefore, if the predicted value of yellow stain is higher than $3.8 \%$, then it will certainly not correspond to a white sample and yellow stain will be present at a $95 \%$ confidence level. There is a $5 \%$ probability of committing a type I or false positive error (analysis of a white sample giving a positive for yellow stain).

The limit of detection is $7.6 \%$, meaning that this the minimum percentage of yellow stain for which we are able to state at a $95 \%$ confidence level that the sample is not white. As described in the previous section, there is a $5 \%$ probability of making a mistake, but in this case, it would be a false negative error (analysis of a sample with yellow stain gives a negative yellow stain).

Fig. 7 shows the different receiver operating characteristic (ROC) curves calculated for Equation 3 and its evolution when the number of samples with yellow stain is reduced. As can be seen, the equation has a very high discrimination capacity, since all curves are very close to the upper left corner. When decreasing the number of samples used to calculate the ROC curves (in Fig. 7 this is equivalent to moving from left to right and from top to bottom), and therefore using lower percentages of yellow stain for the calculation, the discrimination capacity remains high, only decreasing very slightly. The ROC curve calculated using only the 0 and $5 \%$ yellow stain samples is that which is of most interest because the amount of yellow stain present in the production lines is always small, since most of the defective part is removed prior to entering the factory. It can be observed that it maintains a very good discrimination capacity.

In addition to the graphical interpretation of the ROC curves, the area under the ROC curve (AUC) has also been calculated. The AUC values are between 0.9378 and 0.9911 . This statistic confirms that the discrimination capacity of Equation 3 is very high, since values above 0.9 are considered excellent (Hosmer \& Lemeshow 2000, Tape 2000).

The results obtained demonstrate that the NIRS technology is able to detect the
Fig. 7 - Receiver operating characteristic (ROC) curves for Equation 3. From left to right and from top to bottom: ROC curve with all samples; ROC curve with samples of 0-50\%; ROC curve with samples of 0-35\%; ROC curve with samples of 0 25\%; ROC curve with samples of 0-15\%; ROC curve with samples of $0-10 \%$; and ROC curve with samples of $0-5 \%$. The area under the curve (AUC) is showed for each of the calculated ROC curves.
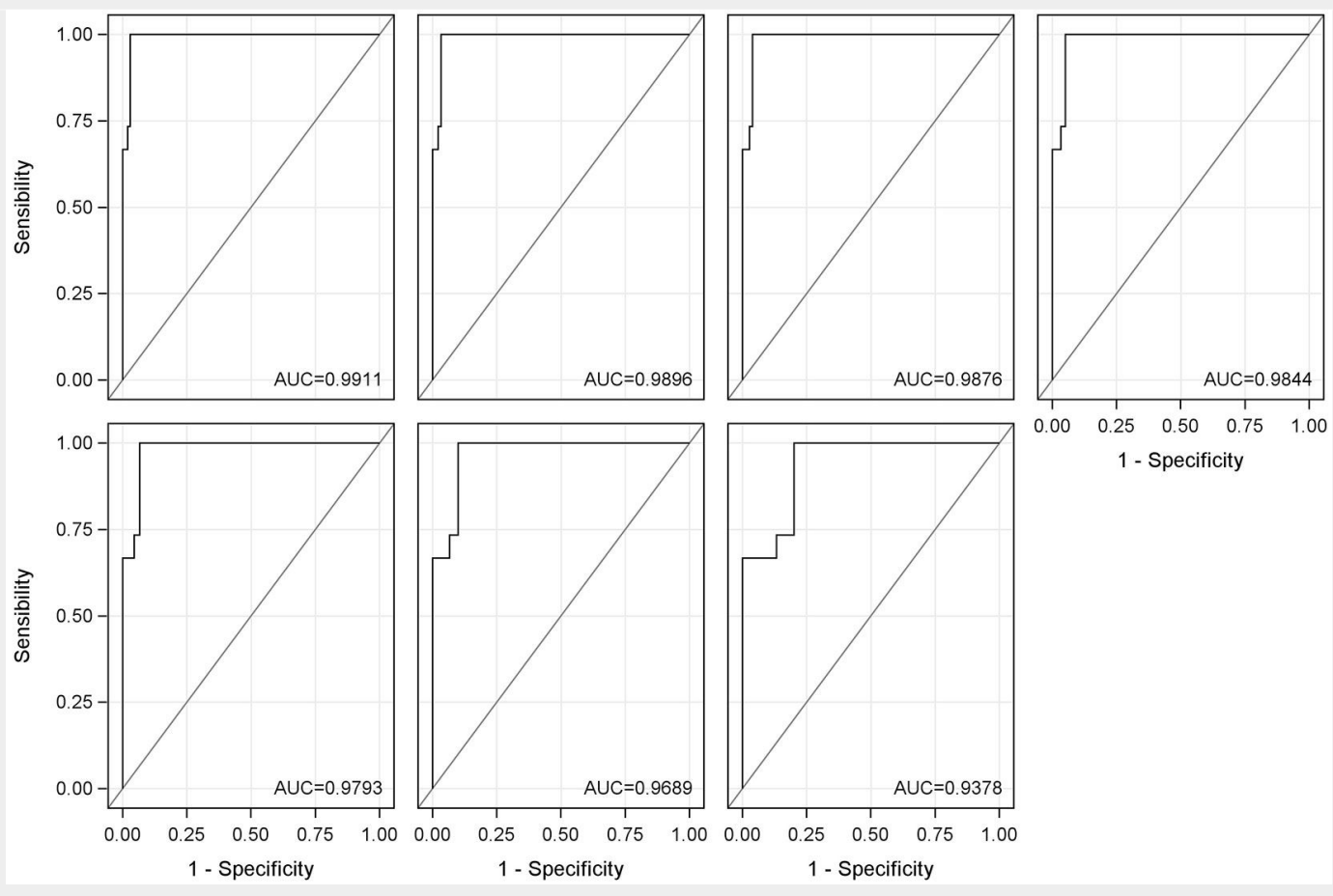
presence of yellow stain and consequently an application able to detect continuously the presence of this anomaly in the lines of granulates industries could be developed. However, it must be taken into account that the models were obtained using just one geographical origin (Catalonia, Spain) and one granulometry $(0.5-1 \mathrm{~mm})$. Therefore, in order to generalize the model on a broader scale, different geographical origins and granulometries should be employed.

\section{Conclusion}

This study evidences the suitability of near infrared spectroscopy (NIRS) as a viable technique for detecting yellow stain in cork granulate. The NIRS equations obtained have a coefficient of determination $\left(R^{2}\right)$ between $98.86 \%$ and $99.42 \%$, a root mean standard error of cross validation (RMSECV) ranging from $3.28 \%$ to $2.34 \%$ and a residual prediction deviation (RPD) above 9. The best result is achieved using standard normal variate (SNV) as preprocessing spectra, entering data exclusively from the near infrared region lying between $9400 \mathrm{~cm}^{-1}$ and $4250 \mathrm{~cm}^{-1}$. This region coincides with the principal absorption peaks of cork granulate. The critical level $\left(L_{c}\right)$ for the best equation is $3.8 \%$, so percentages of yellow stain above $3.8 \%$ can be detected at a $95 \%$ confidence level. The limit of detection $\left(L_{\mathrm{D}}\right)$ is $7.6 \%$, meaning that this value is the minimum percentage of yellow stain that allows to state with $95 \%$ confidence that the sample is not white.

The receiver operating characteristic (ROC) curves show a high discrimination capacity. This capacity is maintained even when samples with a high content of yellow stain are progressively removed. The ROC curve calculated using only 0 and $5 \%$ yellow stain samples still shows a high discrimination capacity. Bearing in mind that most of the cork contaminated with yellow stain is removed in the post-harvest preprocessing, it is important that the equations maintains its discrimination capacity even at the lower percentages given that the presence of this anomaly is always low in cork used for the production of wine stoppers.

The results suggest that NIRS technology may provide a useful method for detecting low concentrations of yellow stain in cork granulate. Batches in which the anomaly has been detected could then be removed at the start of the production line, thus assuring the production of yellow-stain-free cork stoppers. However, further research must be undertaken focusing particularly on the lower percentages of yellow stain in order to improve the accuracy of this technique.

\section{Acknowledgements}

The authors would like to thank the INIACIFOR Cork Laboratory assistants María Luisa Cáceres and Lorenzo Ortiz Buiza for all their work in the laboratory.

\section{References}

APCOR (2016). Yearbook. Web site. [online] URL: http://www.apcor.pt/wp-content/uploads/2016/ 09/Boletim-estatistico-2016.pdf

Barreto MC, Vilas Boas L, Carneiro LC, San Romão MV (2011). Volatile compounds in samples of cork and also produced by selected fungi. Journal of Agricultural and Food Chemistry 59 (12): 6568-6574. - doi: 10.1021/jf200560e Boqué R (2004). El límite de detección de un método analítico [The limit of detection of an analytical method]. Técnicas de Laboratorio 296: 878-881. [in Spanish]

Bordas F (1904). Sur la maladie de la tache jaune des lièges [In the disease of the yellow stain of cork]. Bulletin Académie Sciences 138 (15): 928929. [in French]

Calvo MA, Agut M, Larrondo J, Esteban C, Codina J (1995). Identification of fungal hyphae and conidia in samples of altered cork. Microbios 81 (326): 41-44.

Capone DL, Skouroumounis GK, Sefton MA (2002). Permeation of 2,4,6-trichloroanisole through cork closures in wine bottles. Australian Journal of Grape and Wine Research 8 (3): 196-199. - doi: 10.1111/j.1755-0238.2002.tboo25 $6 . x$

García-Vallejo MC, Varea S, Cadahía E, Fernández-de-Simón B (2001). Influencia de la mancha amarilla sobre la composición química del corcho y la presencia de TCA [Influence of the yellow stain on the chemical composition of the cork and the presence of TCA]. In: Proceedings of the III Spanish Forest Congress "Montes para la Sociedad del Nuevo Milenio" (SECFJunta de Andalucía eds). Granada (Spain), 25-28 Sept 2001. Gráficas Coria, Sevilla, Spain, pp. 5. [in Spanish].

Garcia AR, Lopes LF, De Barros RB, Ilharco LM (2015). The problem of 2,4,6-Trichloroanisole in cork planks studied by attenuated total reflection infrared spectroscopy: proof of concept. Journal of Agricultural and Food Chemistry 63 (1): 128-135. - doi: 10.1021/jf503309a

Gil L (2009). Cork composites: a review. Materials 2 (3): 776-789. - doi: 10.3390/ma2030776 Hosmer DW, Lemeshow S (2000). Applied logistic regression. John Wiley and Sons, USA, pp. 397.

ISO-20752 (2014). Cork stoppers. Determination of releasable 2,4,6-trichloroanisol (TCA). International Organization for Standardization, Geneva, Switzerland, pp. 6.

ISO-22308 (2005). Cork stoppers. Sensory analysis. International Organization for Standardization, Geneva, Switzerland, pp. 5.

Knoll GF (2010). Radiation detection and measurement: student solutions manual. John Wiley and Sons Ltd, USA, pp. 860.

Magwaza LS, Opara UL, Nieuwoudt H, Cronje PJR, Saeys W, Nicolaï B (2012). NIR spectroscopy applications for internal and external quality analysis of citrus fruit. A review. Food and Bioprocess Technology 5 (2): 425-444. - doi: 10.1007/s11947-011-0697-1

Moio L, Diana M, Prete GD, Landa G, Valentino AA, Bianco A (1998). Analysis of volatiles of corks affected by yellow stain and greening and corked wines using GC-sniffing and GC/MS techniques. Industrie delle Bevande 27 (158): 615-619.
Pereira H (2007). Cork: biology, production and uses. Elsevier, Amsterdam, Netherlands, pp. 336.

Pojić MM, Mastilović JS (2013). Near infrared spectroscopy - Advanced analytical tool in wheat breeding, trade and processing. Food and Bioprocess Technology 6 (2): 330-352. - doi: 10.1007/s11947-012-0917-3

Prades C, García-Olmo J, Romero-Prieto T, Ceca J, López-Luque R (2010). Methodology for cork plank characterization (Quercus suber L.) by near-infrared spectroscopy and image analysis. Measurement Science and Technology 21 (6): 065602.

Prades C, Gomez-Sanchez I, Garcia-Olmo J, Gonzalez-Adrados JR (2012). Discriminant analysis of geographical origin of cork planks and stoppers by near infrared spectroscopy. Journal of Wood Chemistry and Technology 32 (1): 54-70. doi: 10.1080/02773813.2011.599697

Prades C, Gómez-Sánchez I, García-Olmo J, González-Hernández F, González-Adrados JR (2014). Application of VIS/NIR spectroscopy for estimating chemical, physical and mechanical properties of cork stoppers. Wood Science and Technology 48 (4): 844-830. - doi: 10.1007/s002 26-014-0642-3

Prades C, Cardillo-Amo E, Beira-Dávila J, SerranoCrespín A, Nuñez-Sánchez N (2017). Evaluation of parameters that determine cork plank quality (Quercus suber L.) by near infrared spectroscopy. Journal of Wood Chemistry and Technology 37 (5): 369-382. - doi: 10.1080/02773813. 2017.1306077

Rocha S, Delgadillo I, Ferrer Correia AJ (1996). GC-MS study of volatiles of normal and microbiologically attacked cork from Quercus suber L. Journal of Agricultural and Food Chemistry 44: 865-871. - doi: 10.1021/jf9500400

Rocha S, Delgadillo I, Ferrer Correia AJ, Barros A, Wells P (1998). Application of an electronic aroma sensing system to cork stopper quality control. Journal of Agricultural and Food Chemistry 46: 145-151. - doi: 10.1021/jf970259+

Sánchez-González JC, García-Olmo J, Prades C (2015). Estimation of moisture curves in cork granulate by Vis/NIRS technology. Wood Science and Technology 49 (5): 1003-1020. - doi: 10.1007/s00226-015-0742-8

Sánchez-González M, García-Olmo J, Prades C (2016). Correlation between porosity of cork planks before and after boiling using near infrared spectroscopy. European Journal of Wood and Wood Products 74 (4): 509-517. - doi: 10.1007/s00107-016-1014-5

Sierra-Pérez J, Boschmonart-Rives J, Gabarrell X (2015). World trade analysis of cork products in the Iberian Peninsula: an economic characterization of a forestry industry. Resources, Conservation and Recycling 98: 55-66. - doi: 10.101 6/j.resconrec.2015.02.011

Slabizki P, Fischer C, Legrum C, Schmarr HG (2015). Characterization of atypical off-flavor compounds in natural cork stoppers by multidimensional gas chromatographic techniques. Journal of Agricultural and Food Chemistry 63 (35): 7840-7848. - doi: 10.1021/acs.jafc.5bo2793 Slabizki P, Legrum C, Wegmann-Herr P, Fischer C, Schmarr HG (2016). Quantification of cork offflavor compounds in natural cork stoppers and wine by multidimensional gas chromatography 
mass spectrometry. European Food Research and Technology 242 (6): 977-986. - doi: 10.1007/ s00217-015-2604-x

Soleas G, Yan J, Seaver T, Goldberg D (2002). Method for the gas chromatographic assay with mass selective detection of trichloro compounds in corks and wines applied to elucidate the potential cause of cork taint. Journal of Agricultural and Food Chemistry 50 (5): 10321039. - doi: 10.1021/jfo11149C

Tape TG (2000). Interpretation of diagnostic tests. Lippincott Williams and Wilkins, Philadelphia, USA, pp. 1026.

UNE-ISO-633 (2010). Corcho. Vocabulario [Cork. Vocabulary]. Asociación Española de Normalización y Certificación, Madrid, Spain, pp. 31. [in Spanish]

Williams PC, Sobering DC (1993). Comparison of commercial near infrared transmittance and reflectance instruments for analysis of whole grains and seeds. Journal of Near Infrared Spectroscopy 1 (1): 25-33. - doi: 10.1255/jnirs.3
Williams PC, Sobering DC (1996). How do we it: brief summary of the methods we use in developing near infrared calibration. In: "Near Infrared Spectroscopy: The Future Waves" (Davis AMC, Williams P eds). NIR Publications, Chichester, UK, pp. 185-188.

Zweig MH, Campbell G (1993). Receiver-operating characteristic (ROC) plots: a fundamental evaluation tool in clinical medicine. Clinical Chemistry 39 (4): 561-577. 